\title{
Spirituality, Personality, and Emotional Distress During COVID-19 Pandemic in Croatia
}

\section{Branimir Margetić ${ }^{1}$ id $\cdot$ Tina Peraica $^{1} \cdot$ Kristina Stojanović $^{1} \cdot$ Dragutin Ivanec $^{2}$}

Accepted: 28 November 2021 / Published online: 7 January 2022

(C) The Author(s), under exclusive licence to Springer Science+Business Media, LLC, part of Springer Nature 2021

\begin{abstract}
This study examined the association between spiritual quality of life (QoL), spiritual coping, emotional distress, and personality during the COVID-19 pandemic lockdown in a convenience sample of Croatian adults ( $n=2,860,80.6 \%$ women). Participants completed an online questionnaire that collected information on sociodemographic characteristics, distress (the Depression, Anxiety, and Stress Scale 21), spiritual coping and spiritual QoL (the WHO Quality of Life-Spirituality, Religiousness, and Personal Beliefs), and personality (the International Personality Item Pool). The hierarchical regression analysis demonstrated that personality traits, especially emotional stability, were the most significant predictors of mental health outcomes. Spiritual coping styles were a predictor of worse, while spiritual QoL of better psychological outcomes. Results demonstrate the complex relations between different aspects of spirituality/religiosity with personality and emotional outcomes and suggest that distress motivates the engagement of spiritual coping in times of disaster.
\end{abstract}

Keywords COVID-19 pandemic · Spiritual coping · Spiritual QoL · Emotional distress · Croatia

Branimir Margetić

branimir.margetic@zg.t-com.hr

Tina Peraica

tina.peraica@gmail.com

Kristina Stojanović

kristina207@gmail.com

Dragutin Ivanec

divanec@ffzg.hr

1 Department of Psychiatry, Clinical Hospital Dubrava, Avenija Gojka Šuška 6, 10000 Zagreb, Croatia

2 Department of Psychology, Faculty of Humanities and Social Sciences, Zagreb, Croatia 


\section{Introduction}

Commonly, disasters have a significant psychological impact on the lives of people affected by them. The Coronavirus disease 2019 (COVID-19) pandemic has jeopardized the physical, psychical, and economic wellbeing of millions of people worldwide. It is well known that factors, such as age, gender, history of psychological distress, and perceived social support (Ursano et al., 2007), are associated with the onset, severity, and persistence of emotional distress in a population affected by a natural disaster. So far, numerous published articles, including meta-analysis (Luo et al., 2020), have explored the psychological consequences of the COVID-19 pandemic. Furthermore, psychological trauma may affect the faith system in different ways. Namely, it may reinforce or undermine religious beliefs and activities (Drescher \& Foy, 1995; Hussain et al., 2011). Reports reveal that better mental health outcomes could be associated with positive religious coping and worse with negative religious coping after natural disasters (Henslee et al., 2015).

Religiosity, per se, is a multi-dimensional construct. As such, difficulties overwhelmingly stand in the way of the smooth realization of research in this field. Different spirituality and religiosity concepts are one aspect of the problem (Blanc et al., 2016). Throughout history, the meaning of the term "spirituality" has been changing. First, the term described distinct religiosity (Koenig et al., 2001). According to the more recent consensus definition: "Spirituality is the aspect of humanity that refers to the way individuals seek and express meaning and purpose and the way they experience their connectedness to the moment, to self, to others, to nature, and to the significant or sacred" (Puchalski et al., 2009). Religion, in contrast, is assumed to be strictly associated with an exact institution and institutionalized practices. Religion is an organized system of beliefs, specific rituals, and symbols that confirm one's closeness to God or a higher power. While spirituality should be viewed as an individual value, religion is related to living in and committing to a community (Koenig et al., 2001). Nevertheless, spirituality and religiosity are highly overlapping terms (Mishra et al., 2017), and a clear distinction has not been established. Consequently, a number of previous studies used the term religiosity/spirituality (Hsu et al., 2009).

Furthermore, de Jager Meezenbroek et al. (2012) reviewed the questionnaires and concluded that practically all of the most commonly used spirituality questionnaires measure religiosity rather than spirituality. There are also serious objections that currently used instruments do not measure religiosity or spirituality but the quality of life (QoL), mental health (Koenig, 2008), and coping styles (Krägeloh et al., 2015).

Generally, and to a large extent, the literature indicates positive religious/spiritual effects on mental health outcomes (e.g. Braam \& Koenig, 2019; Hodapp \& Zwingmann, 2019; Koenig, 2001), or QoL (Panzini et al., 2017). Similarly, a recent review about the influence of religiosity/spirituality on populations traumatized by various disasters also suggests that spirituality and religiosity are associated with more positive outcomes (Aten et al., 2019). However, it has also 
been reported that natural disasters such as a devastating earthquake (Sibley \& Bulbulia, 2012) or tsunami (Hussain et al., 2011) may reinforce and undermine religious faith among the affected population. Furthermore, some reports note that an increased sense of spirituality was associated with less severe posttraumatic stress symptoms in survivors of hurricane Katrina in August 2005 (Haynes et al., 2017). Also, they showed that religious coping was more important for women and less physically capable population after Hurricanes Katrina and Rita (Brown et al., 2010).

This stressful time of the COVID-19 pandemic creates confusion and triggers fear in many individuals who seek answers and the meaning of life. In this regard, a number of articles suggest that religious faith and practices may play an important role in helping individuals to respond to the situation more successfully. For instance, according to Pirutinsky et al. (2020), the COVID-19 pandemic increased the religiosity of American Orthodox Jews. The results showed that while positive religious coping and intrinsic religiosity were associated with less distress, negative religious coping was associated with more distress in that population. Similarly, reports reveal that positive religious coping may have many positive impacts: namely, reducing the risk of developing depressive symptoms in Muslim and Christian populations in the United Arab Emirates (Thomas \& Barbato, 2020); enhancing resilience and wellbeing in the Palestinian population (Mahamid \& Bdier, 2021); and possibly as a significant factor in reducing Malaysian healthcare workers' negative emotions (Chow et al., 2021).

Simultaneously, the results of the studies were somewhat inconsistent with regard to the levels of anxiety in affected populations. For example, associations between religiosity and coronavirus-related anxiety were not found in Portuguese healthcare workers (Prazeres et al., 2021) or nursing students (Savitsky et al., 2020). However, the ultra-Orthodox Jewish population was less anxious and more optimistic (Serfaty et al., 2021). Interesting findings were reported by Rigoli (2021), who found that coronavirus-related anxiety in firm believers increased their religious beliefs but increased skepticism towards religion in non-believers.

Many models of personality are used to improve the understanding and prediction of human behaviour. Previous studies also found associations between spirituality/ religiosity and personality traits. For instance, a meta-analysis of articles that used the Big Five Personality Traits Model (Saroglou, 2002) found that agreeableness and conscientiousness are the factors most frequently associated with religiosity, that extrinsic religiosity was related to low emotional stability, and that spirituality and mature religiosity were associated with high emotional stability. Henningsgaard and Arnau (2008) found associations between spirituality and intrinsic religiosity and agreeableness and conscientiousness but did not associate extrinsic religiosity with personality traits. Scores of self-transcendence, which is a stable personality trait of well-known Cloninger's psychobiological model of personality (Cloninger et al., 1993), characteristically correlate with individual spirituality/religiosity (Garcia-Romeu, 2010). Numerous publications showed relations between mental health and personality. Common features of various researches that have used the Big Five Personality Trait Model indicate associations between emotional stability (opposite from neuroticism) and psychological problems, especially in stress-related 
disorders. In fact, lower average emotional stability scores are related to people with major mental disorders (for review, see Lahey, 2009). We also found that the main predictors of emotional distress in the Croatian population during the COVID-19 pandemic were lower emotional stability scores, higher scores of agreeableness and avoidant coping, lack of active coping, and lack of perceived social support (Margetić et al., 2021). Notwithstanding, no currently available study has investigated relations between spirituality/religiosity, personality, and emotional distress during the COVID-19 pandemic.

\section{Objectives}

Based on the existing literature, we assumed that different dimensions of religiosity/ spirituality (e.g. spiritual coping and spiritual QoL) would be associated with better mental health during the pandemic and that relations between personality traits and different dimensions of religiosity/spirituality would be more specific. Thus, we hypothesized that spiritual coping and spiritual QoL could also predict a better emotional state.

The study's main aim was to evaluate spiritual coping and spiritual QoL as possible predictors of distress during the COVID-19 lockdown in a Croatian convenience sample. The aim was also to learn more about relationships between spiritual coping and spiritual QoL and personality.

\section{Methods}

This study is a part of a larger study. It used a dataset from a previously published study that addressed the relationships between psychological stress, personality, and coping mechanisms (Margetić et al., 2021). Thus, only information relevant to this report is provided, while a more comprehensive description of methods is available in the previously published report.

\section{Procedure}

The researchers used the snowball sampling method for obtaining the sample for web based self-report surveys. Data were collected between 4 and 27th April 2020, during the COVID-19 pandemic lockdown. Participants were informed about the study aims, expected duration, and anonymity of the data. After receiving detailed information about the study, the participants provided electronic informed consent by clicking the "I agree" button. 


\section{Ethics}

The ethics committee of the University Hospital Dubrava, Zagreb, Croatia (No. 2020/3004-02) approved the study, confirming that it was harmonized with the Helsinki Declaration principles.

\section{Instruments}

The WHO Quality of Life-Spirituality, Religiousness and Personal Beliefs (WHOQoLSRPB) is a 32-item self-administered questionnaire (WHOQOL-SRPB Group, 2006). It consists of 8 dimensions (four items per dimension) and uses a 5-point Likert scale (from "not at all" to "extremely"). Scores may be presented as total scores or as scores for each of the eight dimensions. The subsequent analyses by Krägeloh et al. (2015) suggested the appropriateness of a two-factor solution and grouping three dimensions (spiritual connectedness, spiritual strength, faith) together as a spiritual coping factor and the remaining five (life's meaning and purpose, experience of awe and wonder, wholeness and integration, inner peace and hope, and optimism) as a factor of spiritual QoL. The study leans on this modified two-factor structure. Croatian translation has previously been used in research (Mihaljević et al., 2016), and in the current study, Cronbach's $\alpha$ coefficient for the spiritual coping factor was 0.98 and spiritual QoL, 94. It should be noted that, although the questionnaire is based on an international consensus (WHOQOL-SRPB Group, 2006) and is among the most used spirituality scales (Panzini et al., 2017), the scale is also contaminated by indicators of positive mental health (Moreira-Almeida, \& Koenig, 2006).

The Depression, Anxiety, and Stress Scale 21 (DASS-21) (Lovibond \& Lovibond, $1995)$ is a self-reporting instrument that measures emotional distress in three subcategories (depression, anxiety, and stress). It consists of 21 items (seven for each category). It is also based on a four-point rating scale (from $0=$ did not apply to me at all to 3 =applied to me very much or most of the time) that describes the frequency of emotional distress experienced by participants during the week before taking part in the survey. In this study, the Cronbach $\alpha$ coefficients were as follows: depression $=0.91$, anxiety $=0.86$, and stress $=0.90$.

Personality was assessed by the previously validated Croatian version of the International Personality Item Pool (IPIP 50) (Mlačić \& Goldberg, 2007). It consists of 50 items (10 items per Big Five Personality Trait??) and uses a 5-point Likert scale for measuring responses (ranging from $1=$ very inaccurate to $5=$ very accurate). In this study, Cronbach $\alpha$ coefficients of extraversion, agreeableness, conscientiousness, emotional stability, and intellect (openness to experience) were: $0.88,0.83,0.83,0.91$, and 0.80 , respectively. 


\section{Statistical Analysis}

Analyses were conducted using SPSS 25 for Windows (IBM, Chicago, IL, USA). Descriptive analysis included frequencies, means, and standard deviations. Pearson's correlation coefficients determined the bivariate correlations between the variables. A three-step hierarchical regression analysis was performed to estimate the importance of predictor variables on depression, anxiety, and stress: (1) the first step was to assess the contribution of gender and age, (2) the second step, to estimate the contribution of each personality dimension separately/the independent contribution of personality dimensions, and (3) the third step introduced the essential predictors from this study's perspective — spiritual coping and spiritual QoL_to assess their independent contribution to the variance of emotional distress. The distribution of raw data on criteria variables was not as expected. Further, we checked the most important assumption for using regression analysis, i.e. the assumption on the normal distribution of residuals, and this assumption was met. Since there were several missing data, the pairwise approach was used.

\section{Results}

As previously reported (Margetić et al., 2021), 2860 adult Croatian citizens were included in the study, 553 (19.4\%) men, 2,304 (80.6\%) women, and 3 participants did not reply to the gender question. $335(11.7 \%)$ participants were 18-24 years old, 781 (27.4\%) 25-34, 827(29.0\%) 35-44, 588 (20.6\%) 45-54, 271 (9.5\%) $55-64$, and $52(1.8 \%)$ were $65+.6$ participants $(0.2 \%)$ did not reveal their age. DASS-21 subscale scores were: $M=10.37(\mathrm{SD}=10.191)$ for anxiety, $M=12.66$ $(\mathrm{SD}=11.220)$ for depression and $M=16.75(\mathrm{SD}=11.512)$ for stress. Normal

Table 1 Correlation coefficients among variables of interest

\begin{tabular}{lll}
\hline Variables & Spiritual coping & Spiritual QoL \\
\hline Age & $.087 * *$ & $.157 * *$ \\
Sex & $.075^{* *}$ & $.052^{* *}$ \\
DASS stress & $-.116^{* *}$ & $-.392 * *$ \\
DASS anxiety & $-.088^{* *}$ & $-.338^{* *}$ \\
DASS depression & $-.168^{* *}$ & $-.503 * *$ \\
Agreeableness & $.258^{* *}$ & $.353^{* *}$ \\
Extraversion & $.151^{* *}$ & $.381 * *$ \\
Conscientiousness & $.196^{* *}$ & $.322^{* *}$ \\
Emotional stability & $.218^{* *}$ & $.571 * *$ \\
Intellect & $.059^{* *}$ & $.261 * *$ \\
Spiritual coping & & $571 * *$ \\
Spiritual QoL & & 1 \\
\hline
\end{tabular}

Gender: male $=1$, female $=2$; Age: $1=18-24,2=25-34,3=35-44$, $4=45-54,5=55-64,6=\geq 65$

$* * p<.01$ 
levels of depression were present in $64.7 \%$ respondents, anxiety in $71.9 \%$ and stress in $48.2 \%$, while severe to extreme depression was present in $15.9 \%$ of the respondents, severe to extreme anxiety in $10.7 \%$ and severe to extreme stress in $26.2 \%$.

As shown (Table 1), negative correlations between emotional distress (DASS21 subscales scores) were stronger with spiritual QoL than with spiritual coping. Regarding associations between personality traits and spiritual coping and spiritual QoL, the strongest correlation was between spiritual QoL and emotional stability. The strongest correlation of spiritual coping was with agreeableness. All correlations between personality traits and religious/spiritual dimensions were significant, though generally stronger with spiritual QoL than coping.

Table 2 Hierarchical regression analysis on depression, anxiety and stress considering gender, age (step 1), personality dimensions (

\begin{tabular}{|c|c|c|c|c|c|c|}
\hline \multirow[t]{2}{*}{ Step } & \multicolumn{2}{|c|}{ Depression } & \multicolumn{2}{|l|}{ Anxiety } & \multicolumn{2}{|l|}{ Stress } \\
\hline & $\beta$ & $t$ & $\beta$ & $t$ & $\beta$ & $t$ \\
\hline \multicolumn{7}{|l|}{1} \\
\hline Gender & .057 & $2.92 * *$ & .062 & $3.17 * *$ & .068 & $3.52 * *$ \\
\hline Age & -.101 & $-5.50 * *$ & -.068 & $-3.47 * *$ & -.120 & $-6.21 * *$ \\
\hline$\Delta R^{2}$ & $.015^{* *}$ & & $.008^{* *}$ & & $.019^{* *}$ & \\
\hline \multicolumn{7}{|l|}{2} \\
\hline Gender & -.027 & -1.76 & -.012 & -0.73 & -.014 & -0.91 \\
\hline Age & .001 & 0.01 & .024 & 1.04 & -.012 & -0.76 \\
\hline Extraversion & -.109 & $-6.39 * *$ & -.049 & $-2.57 * *$ & -.009 & -0.59 \\
\hline Agreeableness & .098 & $5.99 * *$ & .077 & $4.22 * *$ & .071 & $4.31 * *$ \\
\hline Conscientiousness & -.043 & $-2.73 * *$ & -.001 & -0.06 & -.015 & -0.96 \\
\hline Emotional stability & -.608 & $-36.51 * *$ & -.534 & $-28.89 * *$ & -.638 & $-37.85^{* *}$ \\
\hline Intellect & -.003 & -0.18 & -.005 & -0.30 & -.02 & -1.12 \\
\hline$\Delta R^{2}$ & $.414 * *$ & & $.286^{* *}$ & & $.394 * *$ & \\
\hline \multicolumn{7}{|l|}{3} \\
\hline Gender & -.014 & -0.98 & -.010 & -0.57 & -.011 & -0.74 \\
\hline Age & -.023 & -1.54 & .030 & 1.76 & -.006 & -0.38 \\
\hline Extraversion & -.084 & $-5.07 * *$ & -.040 & $-2.12 *$ & -.001 & -0.06 \\
\hline Agreeableness & .14 & $8.55^{* *}$ & .085 & $4.51 * *$ & .079 & $4.63 * *$ \\
\hline Conscientiousness & -.016 & -1.02 & .005 & 0.29 & -.009 & -0.57 \\
\hline Emotional stability & -.485 & $-26.00 * *$ & -.494 & $-23.13 * *$ & -.602 & $-30.94 * *$ \\
\hline Intellect & .037 & $2.37 *$ & .010 & 0.56 & -.005 & -0.28 \\
\hline Spiritual coping & .085 & $4.75^{* *}$ & .066 & $3.25^{* *}$ & .058 & $3.09 * *$ \\
\hline Spiritual QoL & -.295 & $-12.89 * *$ & -0.108 & $-4.15^{* *}$ & -.099 & $-4.14^{* *}$ \\
\hline$\Delta R^{2}$ & $.035^{* *}$ & & $.005^{* *}$ & & $.004 * *$ & \\
\hline Total $R^{2}$ & $.464 * *$ & & $.300 * *$ & & $.417 * *$ & \\
\hline
\end{tabular}

Gender: male $=1$, female $=2$

$* p<.05 ; * * p<.01$ 
Furthermore, the findings show that women and elderly reported higher spiritual QoL levels and more frequent usage of spiritual coping.

Three separate hierarchical regression analyses were computed to assess the contribution of gender, age, personality, spiritual QoL, and spiritual coping on distress (Table 2). Age and gender were entered in the first step, personality dimensions in the second step, spiritual QoL, and spiritual coping in the third step. The model explained $46.4 \%$ of the total variance for depression, $30 \%$ for anxiety, and $41.7 \%$ for stress. The regression analysis revealed that personality dimensions, especially emotional stability, were the most significant predictors of negative emotions. Simultaneously, the incremental validity of the spiritual coping and spiritual QoL was significant but relatively small.

Results of bivariate correlation analysis (Table 1) showed that lower spiritual QoL and the less frequent use of spiritual coping were related to higher DASS-21 subscales' scores. Nevertheless, in regression analyses (Table 2), better spiritual QoL was a significant independent predictor of better emotional status, while the independent effect of spiritual coping was opposite though relatively weak.

\section{Discussion}

As mentioned above, the study is a part of a previously partially reported (Margetic et al., 2021) more extensive investigation. This paper is focused on examining the predictive effects of spiritual QoL and spiritual coping on emotional distress during the COVID-19 pandemic lockdown and relationships between spiritual coping/ spiritual QoL and personality. As expected, a better spiritual QoL and more frequent spiritual coping usage were associated with less emotional distress (Table 1), which was also in line with much previous evidence (e.g. Gardner et al., 2014; Ramirez et al., 2012). Generally, emotional distress was more strongly associated with spiritual QoL than spiritual coping. As shown, the most significant correlations were between depression and spiritual QoL $(r=-0.503 ; p<0.001)$ (Table 1). Nevertheless, the results should be interpreted cautiously because of substantial overlapping of the item contents in the used scales (Moreira-Almeida, \& Koenig, 2006). Also, as already mentioned, previous studies suggested associations between personality and religiosity/spirituality. In line with previous findings (Henningsgaard \& Arnau, 2008), it was expected that different dimensions of religiosity/spirituality would be more specifically associated with certain personality traits. Due to a relatively large sample, though sometimes rather weak, significant correlations were found between all main personality traits and spiritual QoL and spiritual coping. The fact that associations between personality traits were generally stronger with spiritual QoL than spiritual coping may suggest that spiritual QoL is more closely integrated with stable personal behaviours and values. Furthermore, it is worth mentioning that coping strategies are generally changeable over time (e.g. Fornés-Vives et al., 2016) or could be situation-oriented (e.g. Peñacoba et al., 2018; Stewart \& Schwarzer, 1996). Thus, on a level of a cross-sectional study, the acceptable explanation could be that since coping styles were at least partially affected by the pandemic disaster, their associations with personality were weaker than those between QoL and personality. 
In this regard, further regression analysis revealed that spiritual coping and spiritual QoL were independent predictors of the intensities of negative emotions. However, a better spiritual QoL predicted better psychological conditions, while a more frequent usage of spiritual coping predicted worse emotional conditions (Table 2). A logical explanation for such findings might be that more intense emotional distress symptoms "activate" increased spiritual coping. Accordingly, the findings could be in line with previous notions that distress motivated the engagement of religious coping styles (Kowalczyk et al., 2020; Lucchetti et al., 2020).

Anyway, our findings suggest that spiritual coping can be a significant buffer of negative emotions during lockdown and in an environment of limited social contacts and limited opportunities for contacting mental health professionals. It seems likely that religious organizations may play a significant role in the process of building resilience of the population on such occasions.

Interestingly, findings related to personality traits show that agreeableness was the strongest correlate with spiritual coping $(r=0.258)$ and emotional stability with spiritual QoL $(r=0.571)$. Agreeableness describes individual differences in interpersonal relations. Persons with higher scores are helpful, forgiving, gullible, straightforward, prone to altruism, while those with low scores are rude, suspicious, uncooperative, ruthless, manipulative (Cervone \& Pervin, 2013). Thus, more cooperative and caring people prone to interpersonal compliance were more inclined to use spiritual coping. Emotional stability is a personality trait associated with emotional reactions. Low scores indicate nervous and emotional individuals, those prone to worrying and feelings of insecurity. Higher scores mark calm, stable, and relaxed persons (Cervone \& Pervin, 2013). Findings related to the association between emotional stability and spiritual QoL should not surprise. However, the strength of the correlation ( $r=0.571)$ was substantially higher than expected. On the other hand, high scores related to questions like "How satisfied are you with your personal mind-body-soul balance?" or "How peaceful are you within yourself?" (from "the spiritual QoL subscale") could indicate that calmness or relaxed attitude could be characteristics of personality. Even though this finding is in line with previous findings of the meta-analysis (Saroglou, 2002) that showed that high emotional stability was associated with spirituality and mature religiosity, it also suggests that specific dimensions of spirituality could be especially closely related to emotional stability.

\section{Limitations}

There are serious objections that some questions of the WHOQOL SRPB are, in fact, indicators of mental health outcomes and that the instrument should not be used in studies of mental health outcomes because this is a tautology (Moreira-Almeida $\&$ Koenig, 2006). Furthermore, the studied population was not randomly selected. It included disproportionately more women and highly educated participants. Generally, women are more open to using online social networks (Penni, 2017). The sample of older people, who usually report higher religiosity or spirituality (Zimmer et al., 2016), was lacking. Moreover, Croatia is a country of predominantly Catholic tradition. These factors may limit the generalizability of the findings. Since there 
are differences in WHOQOL-SRPB scores between religious and non-religious individuals (O'Connell \& Skevington, 2010), a lack of information about the strength of religious beliefs is also a limitation. Finally, the cross-sectional nature of the study does not allow conclusions on causal relationships.

\section{Conclusion}

Despite the limitations that call for a cautious interpretation of results, the study shows that the intensity of emotional distress during the pandemic disaster was more closely related to spiritual QoL than spiritual coping. While spiritual QoL predicted better mental health outcomes, spiritual coping was a weak but significant predictor of worse emotional states. Moreover, spiritual QoL was more closely associated with personality traits than spiritual coping, especially with emotional stability, which was the main predictor of mental health outcomes. Accordingly, having in mind that religiosity/spirituality is related to personality traits (probably the main predictors of mental health outcomes), future efforts should be focused on clarifying specific significances of different aspects of religiosity/spirituality when dealing with traumatic events.

\section{Declarations}

Conflict of interest The authors declare that they have no conflict of interest.

\section{References}

Aten, J. D., Smith, W. R., Davis, E. B., Van Tongeren, D. R., Hook, J. N., Davis, D. E., Shannonhouse, L., DeBlaere, C., Ranter, J., O’Grady, K., \& Hill, P. C. (2019). The psychological study of religion and spirituality in a disaster context: A systematic review. Psychological Trauma: Theory, Research, Practice, and Policy, 11(6), 597-613. https://doi.org/10.1037/tra0000431

Blanc, J., Rahill, G. J., Laconi, S., \& Mouchenik, Y. (2016). Religious beliefs, PTSD, depression and resilience in survivors of the 2010 Haiti earthquake. Journal of Affective Disorders, 190, 697-703. https://doi.org/10.1016/j.jad.2015.10.046

Braam, A. W., \& Koenig, H. G. (2019). Religion, spirituality and depression in prospective studies: A systematic review. Journal of Affective Disorders, 257, 428-438. https://doi.org/10.1016/j.jad.2019. 06.063

Brown, J. S., Cherry, K. E., Marks, L. D., Jackson, E. M., Volaufova, J., Lefante, C., \& Jazwinski, S. M. (2010). Louisiana healthy aging study. After hurricanes Katrina and Rita: Gender differences in health and religiosity in middle-aged and older adults. Health Care for Women International, 31(11), 997-1012. https://doi.org/10.1080/07399332.2010.514085

Cervone, D., \& Pervin, L. A. (2013). Trait theory: The five-factor model; applications and evaluation of trait approaches to personality. Wiley.

Cherblanc, J., Bergeron-Leclerc, C., Maltais, D., Cadell, S., Gauthier, G., Labra, O., \& Ouellet-Plamondon, C. (2021). Predictive factors of spiritual quality of life during the COVID-19 pandemic: A multivariate analysis. Journal of Religion and Health, 60(3), 1475-1493. https://doi.org/10.1007/ s10943-021-01233-6

Chow, S. K., Francis, B., Ng, Y. H., Naim, N., Beh, H. C., Ariffin, M. A. A., Yusuf, M. H. M., Lee, J. W., \& Sulaiman, A. H. (2021). Religious coping, depression and anxiety among healthcare workers 
during the COVID-19 pandemic: A Malaysian perspective. Healthcare (basel), 9(1), 79. https://doi. org/10.3390/healthcare9010079

Cloninger, C. R., Svrakic, D. M., \& Przybeck, T. R. (1993). A psychobiological model of temperament and character. Archives of General Psychiatry, 50(12), 975-990. https://doi.org/10.1001/archpsyc. 1993.01820240059008

de Jager Meezenbroek, E., Garssen, B., van den Berg, M., van Dierendonck, D., Visser, A., \& Schaufeli, W. B. (2012). Measuring spirituality as a universal human experience: A review of spirituality questionnaires. Journal of Religion and Health, 51(2), 336-354. https://doi.org/10.1007/ s10943-010-9376-1

Drescher, K. D., \& Foy, D. W. (1995). Spirituality and trauma treatment: Suggestions for including spirituality as a coping resource. National Center for PTSD Clinical Quarterly, 5(1), 4-5.

Fornés-Vives, J., Garcia-Banda, G., Frias-Navarro, D., \& Rosales-Viladrich, G. (2016). Coping, stress, and personality in Spanish nursing students: A longitudinal study. Nurse Education Today, 36, 318323. https://doi.org/10.1016/j.nedt.2015.08.011

Garcia-Romeu, A. (2010). Self-transcendence as a measurable transpersonal construct. Journal of Transpersonal Psychology, 42(1), 26-47.

Gardner, T. M., Christian, U., Krägeloh, C. U., \& Henning, M. A. (2014). Religious coping, stress, and quality of life of Muslim university students in New Zealand. Mental Health, Religion \&amp; Culture, 17(4), 327-338. https://doi.org/10.1080/13674676.2013.804044

Haynes, W. C., Van Tongeren, D. R., Aten, J., Davis, E. B., Davis, D. E., Hook, J. N., Boan, D., \& Johnson, T. (2017). The meaning as a buffer hypothesis: Spiritual meaning attenuates the effect of disaster-related resource loss on posttraumatic stress. Psychology of Religion and Spirituality, 9(4), 446-453. https://doi.org/10.1037/rel0000098

Henningsgaard, J. M., \& Arnau, R. C. (2008). Relationships between religiosity, spirituality, and personality: A multivariate analysis. Personality and Individual Differences, 45(8), 703-708. https://doi. org/10.1016/j.paid.2008.07.004

Henslee, A. M., Coffey, S. F., Schumacher, J. A., Tracy, M., Norris, F. H., \& Galea, S. (2015). Religious coping and psychological and behavioral adjustment after Hurricane Katrina. Journal of Psychology, 149(6), 630-642. https://doi.org/10.1080/00223980.2014.953441

Hodapp, B., \& Zwingmann, C. (2019). Religiosity/spirituality and mental health: A meta-analysis of studies from the German-speaking area. Journal of Religion and Health, 58(6), 1970-1998. https:// doi.org/10.1007/s10943-019-00759-0

Hsu, P. H., Krägeloh, C. U., Shepherd, D., \& Billington, R. (2009). Religion/spirituality and quality of life of international tertiary students in New Zealand: An exploratory study. Mental Health, Religion and Culture, 12(4), 385-399. https://doi.org/10.1080/13674670902752920

Hussain, A., Weisaeth, L., \& Heir, T. (2011). Changes in religious beliefs and the relation of religiosity to posttraumatic stress and life satisfaction after a natural disaster. Social Psychiatry and Psychiatric Epidemiology, 46(10), 1027-1032. https://doi.org/10.1007/s00127-010-0270-7

Koenig, H. G. (2001). Religion and medicine II: Religion, mental health, and related behaviors. International Journal of Psychiatry in Medicine, 31(1), 97-109. https://doi.org/10.2190/ BK1B-18TR-X1NN-36GG

Koenig, H. G. (2008). Concerns about measuring "spirituality" in research. Journal of Nervous and Mental Disease, 196(5), 349-355. https://doi.org/10.1097/NMD.0b013e31816ff796

Koenig, H. G., McCullough, M. E., \& Larson, D. B. (2001). Handbook of religion and health. Oxford University Press.

Kowalczyk, O., Roszkowski, K., Montane, X., Pawliszak, W., Tylkowski, B., \& Bajek, A. (2020). Religion and faith perception in a pandemic of COVID-19. Journal of Religion and Health, 59(6), 2671-2677. https://doi.org/10.1007/s10943-020-01088-3

Krägeloh, C. U., Billington, D. R., Henning, M. A., \& Chai, P. P. (2015). Spiritual quality of life and spiritual coping: Evidence for a two-factor structure of the WHOQOL spirituality, religiousness, and personal beliefs module. Health and Quality of Life Outcomes, 13(1), 1-11. https://doi.org/10.1186/ s12955-015-0212-X

Lahey, B. B. (2009). Public health significance of neuroticism. American Psychologist, 64(4), 241-256. https://doi.org/10.1037/a0015309

Lovibond, S. H., \& Lovibond, P. F. (1995). Manual for the depression anxiety stress scales. Psychology Foundation of Australia.

Lucchetti, G., Góes, L. G., Amaral, S. G., Ganadjian, G. T., Andrade, I., Almeida, P., do Carmo, V. M., \& Manso, M. (2020). Spirituality, religiosity and the mental health consequences of social isolation 
during Covid-19 pandemic. The International journal of social psychiatry. https://doi.org/10.1177/ 0020764020970996

Luo, M., Guo, L., Yu, M., Jiang, W., \& Wang, H. (2020). The psychological and mental impact of coronavirus disease 2019 (COVID-19) on medical staff and general public- A systematic review and meta-analysis. Psychiatry Research, 291, 113190. https://doi.org/10.1016/j.psychres.2020.113190

Mahamid, F. A., \& Bdier, D. (2021). The association between positive religious coping, perceived stress, and depressive symptoms during the spread of Coronavirus (COVID 19) among a sample of adults in Palestine: Across sectional study. Journal of Religion and Health, 60(1), 34-49. https://doi.org/ 10.1007/s10943-020-01121-5

Margetić, B., Peraica, T., Stojanović, K., \& Ivanec, D. (2021). Predictors of emotional distress during the COVID-19 pandemic; a Croatian study. Personality and Individual Differences, 175, 110691. https://doi.org/10.1016/j.paid.2021.110691

Mihaljević, S., Aukst-Margetić, B., Karničnik, S., Vuksan-Ćusa, B., \& Milošević, M. (2016). Do spirituality and religiousness differ with regard to personality and recovery from depression? A follow-up study. Comprehensive Psychiatry, 70, 17-24. https://doi.org/10.1016/j.comppsych.2016.06.003

Mishra, S. K., Togneri, E., Tripathi, B., \& Trikamji, M. B. (2017). Spirituality and religiosity and its role in health and diseases. Journal of Religion and Health, 56(4), 1282-1301. https://doi.org/10.1007/ s10943-015-0100-Z

Mlačić, B., \& Goldberg, L. R. (2007). An analysis of a cross-cultural personality inventory: The IPIP bigfive factor markers in Croatia. Journal of Personality Assessment, 88(2), 168-177. https://doi.org/ $10.1080 / 00223890701267993$

Moreira-Almeida, A., \& Koenig, H. G. (2006). Retaining the meaning of the words religiousness and spirituality: A commentary on the WHOQOL SRPB group's "A cross-cultural study of spirituality, religion, and personal beliefs as components of quality of life" (62: 6, 2005, 1486-1497). Social Science \&amp; Medicine, 63(4), 843-845. https://doi.org/10.1016/j.socscimed.2006.03.001

O'Connell, K. A., \& Skevington, S. M. (2010). Spiritual, religious, and personal beliefs are important and distinctive to assessing quality of life in health: A comparison of theoretical models. British Journal of Health Psychology, 15(Pt4), 729-748. https://doi.org/10.1348/135910709X479799

Panzini, R. G., Mosqueiro, B. P., Zimpel, R. R., Bandeira, D. R., Rocha, N. S., \& Fleck, M. P. (2017). Quality-of-life and spirituality. International Review of Psychiatry, 29(3), 263-282. https://doi.org/ 10.1080/09540261.2017.1285553

Peñacoba, C., Rodríguez, L., Carmona, J., \& Marín, D. (2018). Agreeableness and pregnancy: Relations with coping and psychiatric symptoms, a longitudinal study on Spanish pregnant women. Women and Health, 58(2), 204-220. https://doi.org/10.1080/03630242.2017.1282397

Penni, J. (2017). The future of online social networks (OSN): A measurement analysis using social media tools and application. Telematics and Informatics, 34(5), 498-517. https://doi.org/10.1016/j.tele. 2016.10.009

Pirutinsky, S., Cherniak, A. D., \& Rosmarin, D. H. (2020). COVID 19, mental health, and religious coping among American Orthodox Jews. Journal of Religion and Health, 59(5), 2288-2301. https://doi. org/10.1007/s10943-020-01070-Z

Prazeres, F., Passos, L., Simões, J. A., Simões, P., Martins, C., \& Teixeira, A. (2020). COVID-19- related fear and anxiety: Spiritual-religious coping in healthcare workers in Portugal. International Journal of Environmental Research and Public Health, 18(1), 220. https://doi.org/10.3390/ijerph18010220

Puchalski, C., Ferrell, B., Virani, R., Otis-Green, S., Baird, P., Bull, J., Chochinov, H., Handzo, G., Nelson-Becker, H., Prince-Paul, M., Pugliese, K., \& Sulmasy, D. (2009). Improving the quality of spiritual care as a dimension of palliative care: The report of the consensus conference. Journal of Palliative Medicine, 12(10), 885-904. https://doi.org/10.1089/jpm.2009.0142

Ramirez, S. P., Macêdo, D. S., Sales, P. M., Figueiredo, S. M., Daher, E. F., Araújo, S. M., Pargament, K. I., Hyphantis, T. N., \& Carvalho, A. F. (2012). The relationship between religious coping, psychological distress and quality of life in hemodialysis patients. Journal of Psychosomatic Research, 72(2), 129-135. https://doi.org/10.1016/j.jpsychores.2011.11.012

Rigoli, F. (2021). The link COVID-19, anxiety, and religious beliefs in the United States and the United Kingdom. Journal of Religion and Health, 60(4), 2196-2208. https://doi.org/10.1007/ s10943-021-01296-5

Serfaty, D. R., Lugasi, T., \& Strous, R. D. (2021). Anxiety reactions and coping modalities with the COVID-19 pandemic: A cross-sectional study comparing a population of religious patients with mental illness and their health caregivers. Journal of Religion and Health, 60(3), 1494-1506. https://doi.org/10.1007/s10943-021-01219-4 
Saroglou, V. (2002). Religion and the five factors of personality: A meta-analytic review. Personality and Individual Differences, 32(1), 15-25. https://doi.org/10.1016/S0191-8869(00)00233-6

Savitsky, B., Findling, Y., Ereli, A., \& Hendel, T. (2020). Anxiety and coping strategies among nursing students during the covid-19 pandemic. Nurse Education in Practice, 46, 102809. https://doi.org/10. 1016/j.nepr.2020.102809

Sibley, C. G., \& Bulbulia, J. (2012). Faith after an earthquake: A longitudinal study of religion and perceived health before and after the 2011 Christchurch New Zealand Earthquake. PLoS ONE, 7(12), e49648. https://doi.org/10.1371/journal.pone.0049648

Stewart, S. M., \& Schwarzer, R. (1996). Stability of coping in Hong Kong medical students: A longitudinal study. Personality and Individual Differences, 20(2), 245-255. https://doi.org/10.1016/01918869(95)00162-X

Thomas, J., \& Barbato, M. (2020). Positive religious coping and mental health among Christians and Muslims in response to the COVID-19 pandemic. Religions, 11(10), 498. https://doi.org/10.3390/ rel11100498

Ursano, R. J., Fullerton, C. S., Weisaeth, L., \& Raphael, B. (2007). Individual and community responses to disasters. In R. J. Ursano, C. S. Fullerton, L. Weisaeth, \& R. Beverley (Eds.), Textbook of disaster psychiatry (pp. 3-28). Cambridge University Press.

WHOQOL SRPB Group. (2006). A cross-cultural study of spirituality, religion, and personal beliefs as components of quality of life. Social Science \&amp; Medicine, 62(6), 1486-1497. https://doi.org/ 10.1016/j.socscimed.2005.08.001

Zimmer, Z., Jagger, C., Chiu, C. T., Ofstedal, M. B., Rojo, F., \& Saito, Y. (2016). Spirituality, religiosity, aging and health in global perspective: A review. SSM - Population Health, 2, 373-381. https://doi. org/10.1016/j.ssmph.2016.04.009

Publisher's Note Springer Nature remains neutral with regard to jurisdictional claims in published maps and institutional affiliations. 